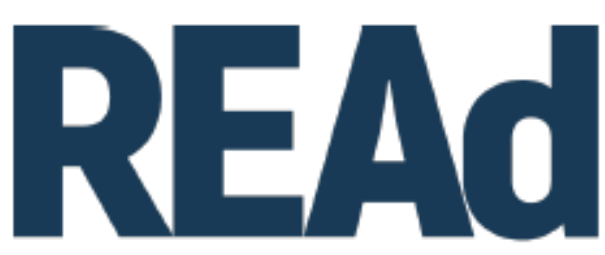

Revista Eletrônica de Administração

\title{
ORGANIZAÇÃO COMO EVENTO: IMPLICAÇÕES CONCEITUAIS E TEÓRICAS DA ADOÇÃO DE UMA ONTOLOGIA PROCESSUAL STRONG-VIEW ${ }^{1}$
}

\author{
Karine Francisconi Chaerki ${ }^{2}$ \\ Queila Regina Souza Matitz ${ }^{3}$
}

http://dx.doi.org/10.1590/1413-2311.322.102252

\begin{abstract}
RESUMO
Estudos organizacionais com base em metafísica processual têm gerado crescente interesse ao longo das últimas décadas. Segundo essa perspectiva ontológica, uma visão processual demanda a substituição de explicações simplificadoras da realidade fundamentadas na ideia de substância por explicações mais complexas com base na noção de processo e de relacionalidade. O objetivo central deste artigo consiste em discutir implicações da adoção de uma noção de evento de base ontológica processual strong-view no campo de estudos organizacionais. Para tanto, foi desenvolvido um ensaio teórico fundamentado na: (i) exploração do conceito de evento com base na ontologia processual de Alfred North Whitehead e (ii) identificação de possibilidades da adoção dessa noção de evento para os estudos organizacionais. Como principal resultado do trabalho, destaca-se a discussão de seis princípios ou proposições relacionadas ao conceito de organização com base nessa noção strong-view de evento: organização como estrutura de eventos, ontologia organizacional ancorada em sua temporalidade, eventos como unidades de análise organizacional, organização como processo contínuo, organização como resultado de mecanismos de estabilização dinâmica, organização como reiteração de padrões.
\end{abstract}

Palavras-chave: Evento. Ontologia processual. Whitehead. Organização.

\section{ORGANIZATION AS EVENT: CONCEPTUAL AND THEORETICAL IMPLICATIONS OF THE ADOPTION OF A STRONG-VIEW PROCESSUAL ONTOLOGY}

\footnotetext{
${ }^{1}$ Recebido em 22/4/2020, aceito em 16/3/2021.

${ }^{2}$ Universidade Federal do Paraná - Programa de Pós-Graduação em Administração; Curitiba - PR (Brasil); http://orcid.org/0000-0003-1414-7647; k.francisconi@ gmail.com.

${ }^{3}$ Universidade Federal do Paraná - Programa de Pós-Graduação em Administração; Curitiba - PR (Brasil); http://orcid.org/0000-0001-5818-4701; queila.matitz@ gmail.com. 
Organizational studies based on process metaphysics generated increasing interest over the past few decades. According to this ontological perspective, a process view demands the replacement of simplifying explanations of reality based on the idea of substance by more complex explanations based on the notion of process and relationality. The main objective of this article is to discuss implications of the adoption of an event-based theory from a strongview process ontological basis in the field of organizational studies. To this end, this theoretical essay was developed based on (i) exploration of the concept of event based on the process ontology of Alfred North Whitehead and (ii) identification of implications of the adoption of this event-based theory for organizational studies. As the main result of the work, we highlight the discussion of six principles or propositions related to the concept of organization based on this strong-view notion of event: organization as a structure of events, organizational ontology anchored in its temporality, events as units of organizational analysis, the organization as a continuous process, the organization as a result of dynamic stabilization mechanisms, the organization as the reiteration of standards.

Keywords: Event. Processual ontology. Whitehead. Organization.

\section{LA NOCIÓN DE EVENTO EN ESTUDIOS DE ADMINISTRACIÓN Y ORGANIZACIÓN: POSIBILIDADES DE ADOPTAR UN PROCESO DE STRONG- VIEW}

Los estudios organizativos basados en la metafísica del proceso han suscitado un interés creciente en las últimas décadas. Según esta perspectiva ontológica, una visión de proceso exige la sustitución de las explicaciones simplificadoras de la realidad basadas en la idea de sustancia por explicaciones más complejas basadas en la noción de proceso y relacionalidad. El objetivo principal de este artículo es discutir las implicaciones de la adopción de una teoría basada en el evento desde una base ontológica de proceso de visión fuerte en el campo de los estudios organizacionales. Para ello, este ensayo teórico se ha desarrollado a partir de (i) la exploración del concepto de evento a partir de la ontología del proceso de Alfred North Whitehead y (ii) la identificación de las implicaciones de la adopción de esta teoría basada en el evento para los estudios organizacionales. Como principal resultado del trabajo, destacamos la discusión de seis principios o proposiciones relacionadas con el concepto de organización a partir de esta noción de evento de visión fuerte: la organización como estructura de eventos, la ontología organizacional anclada en su temporalidad, los eventos como unidades de análisis organizacional, la organización como proceso continuo, la organización como resultado de mecanismos de estabilización dinámica, la organización como reiteración de normas.

Palabras clave: Evento. Ontología procesal. Whitehead. Organización. 


\section{INTRODUÇÃO}

O crescente reconhecimento da importância das questões epistemológicas para a pesquisa organizacional reflete um movimento em direção à necessidade de compreensão dos limites e potencialidades desse campo de estudos. Dentre as discussões recentes, o uso da linguagem científica na atribuição de significados aos fenômenos organizacionais foi foco de problematização e crítica por Matitz e Vizeu (2012). Com base na história conceitual de Koselleck (1992) e na filosofia do conhecimento de Foucault (1999), os autores destacaram, entre outros aspectos, a importância da definição conceitual no campo de estudos organizacionais, sob as perspectivas histórica e social. Historicamente, outros autores têm discutido a importância dos conceitos enquanto elementos essenciais ao fazer científico e à comunicação científica. (SELTTIZ et al., 1974; GOODE; HATT, 1979).

Entretanto, ao contrário de outras áreas da ciência cujos léxicos especializados parecem suficientemente definidos, o campo das ciências sociais é caracterizado pela dificuldade - e em certa medida pela impossibilidade — de se definirem termos exclusivamente associados a fenômenos específicos. É o caso de palavras aplicadas à designação de fenômenos frequentemente utilizados nos campos de administração e de estudos organizacionais tais como “organização”, “processo", “cultura”, “estrutura”, dentre outros.

Recentemente, uma interseção entre o campo de estudos organizacionais e a Filosofia do Processo chamou nossa atenção para um fenômeno em particular: o uso da noção de evento. A questão do evento vem sendo apontada por estudiosos há algumas décadas (VAN DE VEN; POOLE, 1990; CHIA; KING, 1998; DURANT; VAARA, 2009; HERNES, 2014a; 2014b) e mais recentemente por Morgeson; Mitchell e Liu (2015), Hussenot e Missonier (2016) e Hernes (2017; 2020). Com base nas ideias de Alfred North Whitehead, esses e outros autores têm proposto a utilização de uma noção de evento de base processual strong-view como fundamento para estudos organizacionais (HERNES, 2014a, 2020; HUSSENOT; MISSONIER, 2016). Uma strong-view do processo é fundamentada em uma ontologia de becoming, em lugar de uma ontologia do "ser" (being). Sob esse ponto de vista, a transformação é constante: organizações

e indivíduos “existem” apenas como estabilizações temporárias dos processos em curso (HARDY; THOMAS, 2017) ou, em outras palavras, apresentam plasticidade dinâmica.

Realizamos uma revisão de literatura em um corpus de análise formado por 710 artigos e identificamos 7.777 incidências do termo "evento" em trabalhos publicados entre 2012 e 
2017 em periódicos nacionais e internacionais ${ }^{4}$ indexados e integrantes do extrato A do Qualis Capes. Ressalte-se que praticamente $50 \%$ de todos os artigos publicados nesses periódicos no período considerado faziam alguma menção ao termo "evento". Como resultado da análise qualitativa e indutiva do corpus textual, observamos a diversidade de significados atribuídos ao termo: embora quase todas as definições incluam referência a um tipo de acontecimento ou ação, são distintas na medida em que apontam para diferentes aspectos ou atributos relacionais ao fenômeno. Por exemplo, há distinções em termos temporais na medida em que o fato ou acontecimento pode estar localizado no passado, no presente ou no futuro. Também há distinções em termos de intencionalidade e frequência, pois os eventos podem estar relacionados a diferentes tipos de atividades: intencional e rara, não intencional e rara, intencional e repetitiva, não intencional e repetitiva, etc.

Quanto aos efeitos, os eventos podem gerar expectativas e experiências sociais positivas ou negativas, duradouras ou transitórias. Entretanto, chama a atenção o uso não especializado do termo. Ou seja, privilegia-se a utilização do significado de evento conforme o senso comum. Observamos, ainda, baixa frequência de uso da noção de evento conforme proposta pela Filosofia do Processo de Whitehead. No total, foram identificadas menções do termo "evento" no contexto da strong-view de estudos de processo em apenas 12 artigos dentre os 710 analisados, o que corresponde a $1,7 \%$ do total. Há, portanto, um campo de estudos praticamente inexplorado em torno do assunto.

Nosso propósito central, portanto, a partir desses achados e de um interesse crescente na superação da hegemonia funcionalista no campo de estudos de administração, foi apresentar possibilidades da adoção de uma noção de evento de base ontológica processual strong-view, especialmente para o campo de estudos organizacionais.

Metodologicamente, adotamos uma estrutura de ensaio teórico para apresentação do conceito de evento conforme proposta pela ontologia processual de Alfred North Whitehead e para descrição de possibilidades da adoção dessa noção para os estudos organizacionais.

Quanto à estrutura do trabalho, a seção 1 apresenta fundamentos ontológicos processuais da noção de evento proposta por Whitehead. A seção 2 descreve possibilidades de adoção da noção de evento de base processual strong-view para os estudos organizacionais. Por fim, na seção seguinte concluímos o trabalho, destacando a necessidade da realização de estudos futuros voltados à exploração das implicações e possibilidades teóricas e metodológicas

\footnotetext{
${ }^{4}$ Academy of Management Journal (AMJ), Academy of Management Review (AMR), Organization Studies (OS), Organizações \& Sociedade, Revista de Administração Contemporânea (RAC) e Revista de Administração de Empresas (RAE). 
das aplicações da Filosofia do Processo e, mais especificamente, da noção de evento de base processual, em pesquisas dos campos de administração e de estudos organizacionais.

\section{A NOÇÃO DE EVENTO À LUZ DA FILOSOFIA DO PROCESSO DE WHITEHEAD}

Os trabalhos de Alfred North Whitehead constituem um marco da Filosofia do Processo do início do século XX. Seus pensamentos impulsionam pesquisadores da área de Estudos Organizacionais em busca de uma estrutura expandida nos estudos de processo (HELIN; HERNES; HJORTH; HOLT, 2014; HERNES, 2008). Matemático e lógico de origem britânica, Whitehead dedicou grande parte de suas investigações ao estudo da noção processual dos eventos nos livros “O conceito de Natureza” (1993) e "Processo e realidade” (1978).

Sob o ponto de vista do autor, o fenômeno "processo" pode ser entendido de duas formas. Em um mundo feito de coisas, os processos representam mudanças nessas coisas enquanto, em um mundo feito de processos, representam um contínuo "tornando-se" do próprio mundo. Para Whitehead (1929, 1993), o mundo não é uma coisa ou substância estável, mas um processo. Ao contrário do pensamento científico cartesiano, fundamentado em completude das substâncias estáveis, o mundo visto sob as lentes da Filosofia do Processo é composto por interconectividades infinitas, por ambiguidade e incerteza, por transformação e constante "vindo a ser" (becoming).

Para Whitehead (1978), os eventos são a última versão da realidade (não no sentido de “verdade”, mas no sentido de percepção humana da realidade). Logo, a noção de evento é distinta da ideia de fatos isolados ligados por relações de causalidade e em sequência linear. Os eventos, sob o ponto de vista da strong-view de processo, são extensões de actual occasions ${ }^{5}$ ao longo do espaço e do tempo, as quais tornam-se perceptíveis para os atores que compõem os eventos: “[...] o que percebemos é sempre a relação ou conexão entre as coisas e os eventos." (HOLT; MUELLER $^{6}$, 2011 apud HUSSENOT; MISSONIER, 2016, p. 527). Em outras palavras, os eventos são as unidades sensíveis necessárias ao entendimento do mundo como uma realidade em constante becoming. São as coisas finais das quais o mundo é feito. São também origens das abstrações que fazemos a respeito do tempo, do espaço e das coisas ou

\footnotetext{
${ }^{5}$ Actual occasions são partículas invisíveis similares à ideia de átomos e surgem (ou become) como 'flashes' de duração temporal instantânea, para então desaparecerem e se tornarem novas actual occasions.

${ }^{6}$ HOLT, R.; MUELLER, F. Wittgenstein, Heidegger and drawing lines in organization studies. Organization Studies, v. 32, p. 67-84, 2011.
} 
entidades. Os eventos, por sua vez, são interconectados ou "emaranhados" de tal forma a constituírem os processos.

Os eventos mantêm a fluidez necessária para o processo de teorização na medida em que se constituem por um conjunto de entidades espaço-temporais com certa duração e significado que gera padrões sintetizados pela apreensão sensível. (HERNES, 2014a). A rigor, as únicas unidades de análise possíveis para produção de conhecimento a respeito do mundo são os eventos: experiência do ser humano quando em interação com a realidade. Entretanto, é necessário que os eventos se conectem a fim de formar algum tipo de estrutura ou padrão significativo ao longo do tempo e do espaço (HERNES, 2008). Sob esse ponto de vista, a noção de causalidade é invertida na medida em que a atividade da "causa" fica suspensa no presente:

De acordo com Whitehead, a causa não pode ser o elemento ativo [em uma relação de causalidade] porque naquele momento crucial do tempo, a atividade da causa já cessou e está finalizada. O elemento ativo não é o passado, mas a realidade presente, a qual está em processo de becoming por meio da evocação do evento 'causal' ou 'influente'. (HERNES, 2014b, p. 262, tradução nossa).

A Figura 1, a seguir, é uma tentativa de ilustrar graficamente o conceito de actual occasions, por meio da comparação entre uma visão "tradicional'” de processo — a qual toma como base o deslocamento temporal de substâncias estáveis - versus uma visão processual de realidade, com base no surgimento e esvanecimento de actual occasions. Em seguida, a Figura 2 ilustra as noções de evento, processo e objeto/entidade com base na visão processual de realidade proposta por Whitehead (1978). 
Figura 1 - representação gráfica da visão processual de realidade de Alfred North Whitehead

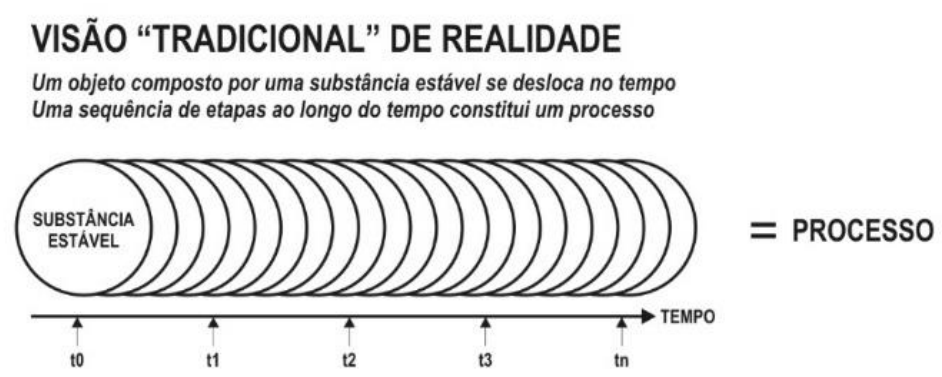

\section{VISÃO PROCESSUAL DE REALIDADE}

Actual occasions (partículas de duração temporal instantânea) desaparecem e fornecem "dados" a outras particulas, formando unidades perceptiveis, os eventos

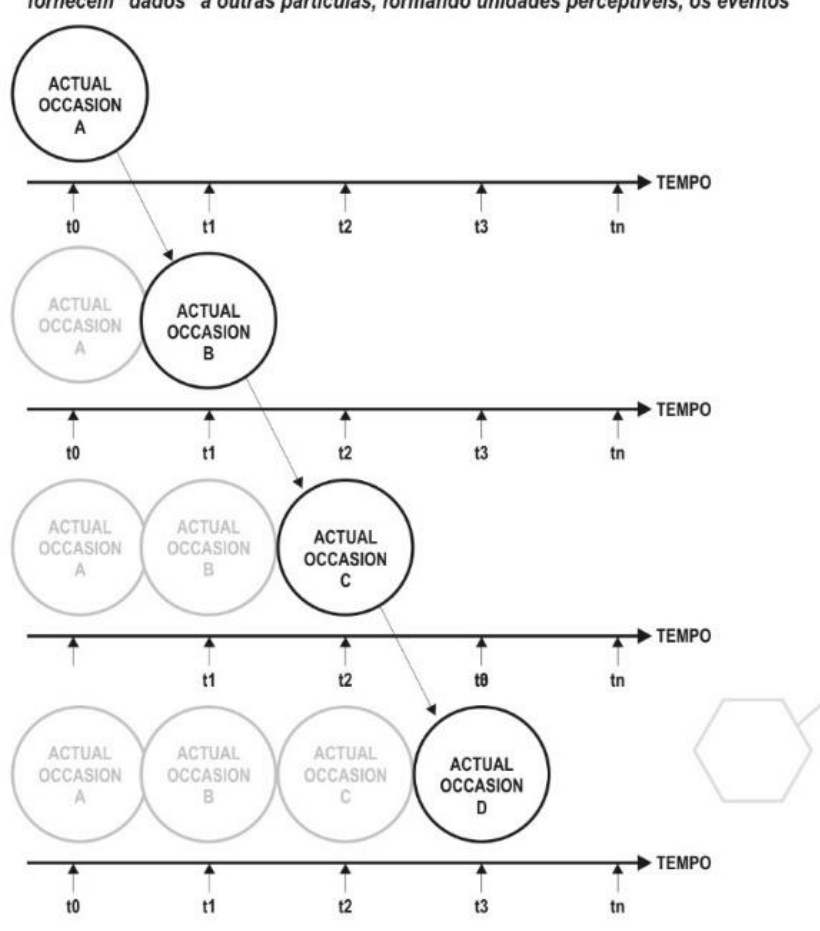

Fonte: Elaborado pelos autores (2020).

Um evento, portanto, é uma entidade espaço-temporal com certa duração (não extensão linear no tempo, porque não pode ser experimentada novamente) limitada pela simultaneidade: encontro entre entidades durante o presente. Em outras palavras, as ocasiões 'tterminam', mas persistem sob a forma de dados ou "restos" de informações de ocasiões passadas. Para Whitehead (1929), "um evento não é cópia passiva do passado, ao contrário, no ato de autocriação refresca-se o projeto do passado, inventa-se assim seu presente original e preparase para as aspirações futuras”. (HERNES, 2014a, p. 92, grifo no original, tradução nossa).

Os eventos também podem ser mais concretamente analisados dentro de eventos menores dos quais são compostos. Por exemplo, uma conversa pode ser analisada por meio da 
experiência dos participantes. A experiência dos participantes, por sua vez, pode ser analisada por meio de uma sequência temporal de eventos. Um momento desta experiência temporalmente estendida é um singelo evento que pode ser analisado em suas partes, mas não por meio de ocasiões completas, "porque a ocasião momentânea da experiência é atômica". (COOB JR., 2008, p. 23, tradução nossa). Um evento, portanto, é composto de outros eventos, ou partículas de eventos.

Figura 2 - representação gráfica das noções de evento, processo e objeto/entidade à luz da visão processual de realidade de Alfred North Whitehead
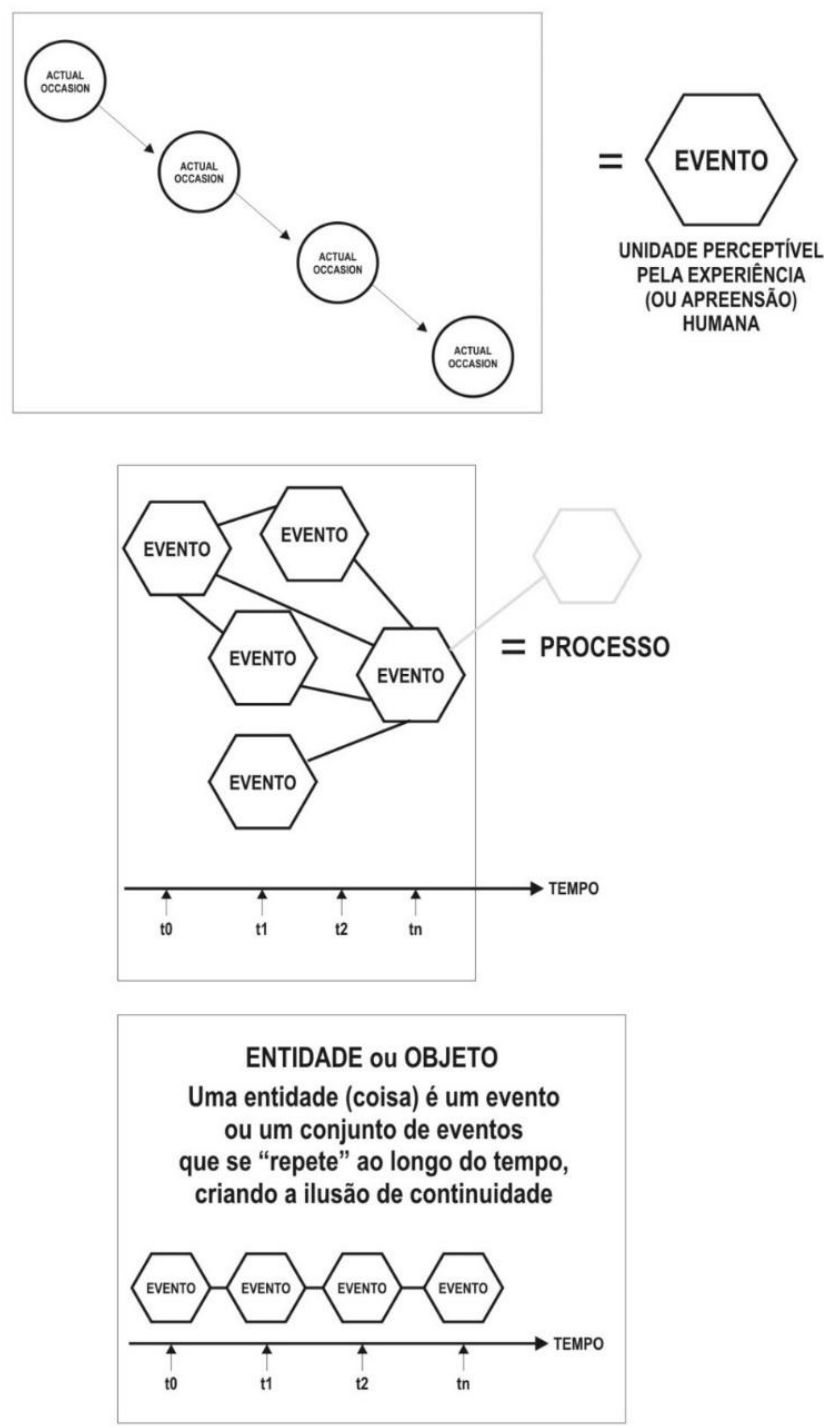

Fonte: Elaborado pelos autores (2020).

A distinção entre evento e entidade é importante para a compreensão da ontologia de processo proposta por Whitehead (1929). As entidades são essas coisas que podem ser reconhecidas com certa estabilidade, sem serem tidas com status ontológico de serem sempre 
estáveis. Por exemplo: os papéis dados às pessoas para executarem suas tarefas duram mais que a presença da pessoa. Assim os papéis formais são independentes de seus titulares. No entanto, não há papéis sem pessoas para preenchê-los. Um cargo criado à espera de um candidato pode ser visto como uma entidade " neutra". Mas, uma vez preenchido, a pessoa que o ocupa dá-lhe um conteúdo diferente do conteúdo que outra pessoa teria dado. Logo, a combinação pessoacargo torna-se única. Além disso, essa combinação se torna diferente assim que se conecta com outras coisas para formar um todo maior, ao mesmo tempo em que forma uma continuidade com o que era antes. Em outras palavras, os objetos ou coisas são algo que "se pode falar a respeito" por serem diferentes de outras coisas. Uma coisa pode ser um objeto material, mas também pode ser um estado de coisas, um conceito, uma pessoa, um papel, uma organização, ou uma marca. Uma coisa é algo em si, cujo sentido se dá quando vista como parte de um todo. Este todo que uma coisa faz parte é o que Whitehead (1978) chama de unidade complexa: uma mistura heterogênea em constante mudança, relativamente estável sem composição específica. (HERNES, 2014a).

\subsection{CONEXÃO ENTRE EVENTOS: PREHENSION E FEELING}

Os eventos constituem pontos no tempo-espaço e servem para marcar o becoming do processo das entidades, ou seja, indicam relações entre as entidades. Além disso, eventos são ao mesmo tempo marcadores e geradores de processos. Como indicadores, os eventos influenciam a evolução dos processos: fornecem dados ${ }^{7}$ para o futuro e marcam os objetivos de processos, tais como a realização de objetivos ou prazos de um planejamento. Em ambos os casos, os eventos são marcadores de processos, enquanto participam ativamente da formação desses processos. (HERNES, 2008).

No processo de becoming, os eventos captam uns aos outros. A força que conecta os eventos no espaço temporal é denominada apreensão (prehension) (HERNES, 2008), a qual reproduz o passado e o transporta para o futuro. Desse modo, as configurações mais estáveis se desenvolvem. Uma vez que certos padrões são iniciados, tendem a registrar outros eventos como objetos comuns em sua configuração. Para Whitehead (1929), cada evento carrega consigo os dados "congelados" de seus predecessores e acrescenta novos feelings ${ }^{8}$ ou

\footnotetext{
${ }^{7}$ Dados significa o conteúdo objetivo percebido na experiência presente.

${ }^{8} \mathrm{O}$ significado de feeling em Whitehead é aplicável a eventos humanos e não humanos. Nesse sentido, uma cadeira feita de madeira pode manifestar feelings em relação à umidade do ambiente e iniciar um processo (aqui entendido como conjunto de eventos interconectados) de deterioração.
} 
impressões/sensações. Logo, o futuro não é determinado, pois existe uma gama de possibilidades e probabilidades de becoming. Toda gota de experiência (actual entitiy) tem o poder de decidir entre as alternativas de futuro. (LANGLEY; TSOUKAS, 2017). Por exemplo, a legitimidade sob a forma de valores sociais é importante para os eventos subsequentes, pois permite que modelos institucionalizados se difundam. Mas não há um estado final. Tudo é meramente um estágio de formação ou de potencialidade para outros processos. (HERNES, 2008). Por exemplo, no processo de tomada de decisão, apreensão significa que as decisões se conectam às soluções e aos problemas mais prováveis com base em decisões anteriores.

A aproximação dos eventos permite a realização de novos eventos ao assumirem qualidades relacionais associadas a significados e feelings que lhes permitem conectar-se espaço-temporalmente. Whitehead (1978) explica que um feeling é como um vetor para um evento, tornando-o agência para o desenvolvimento de novos eventos. A agência provinda de umfeeling forte torna mais provável as conexões entre eventos. (HERNES, 2008). Por exemplo, uma sugestão de mudança que "faça sentido" para os atores 9 envolvidos em uma atividade no contexto organizacional terá mais probabilidade de ser aceita e implementada.

A Figura 3 procura demonstrar a intensidade do sentimento para a criação de eventos. Uma intensidade mais alta significa uma capacidade de agência mais forte na formação de eventos.

Figura 3 - probabilidade de conexão entre eventos: feeling e prehension
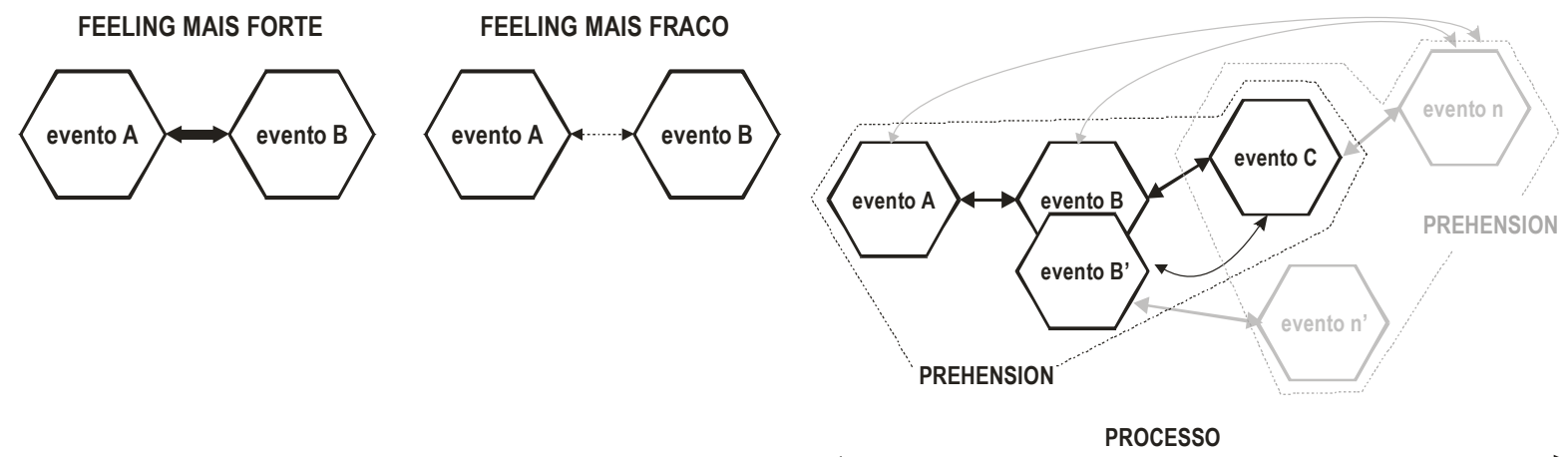

\footnotetext{
${ }^{9}$ Hernes (2008, p. viii) considera todos os tipos de atores na relação organizacional: humanos, tecnologias, conceitos, marcas, grupos e afins em totalidades significativas. Essas totalidades significativas podem ser uma comunidade no Twitter, um grupo de interesse emergente, um empreendedor com uma ideia, um laboratório de ideias (think tank), um desfile de moda, interações esporádicas entre atores dispersos em torno de um conceito, ou a propagação de uma tecnologia, assim como qualquer forma de organização formal ou instituição. Totalidades significativas não são entidades como tal, mas podem ser temporariamente experimentadas como entidades.
} 


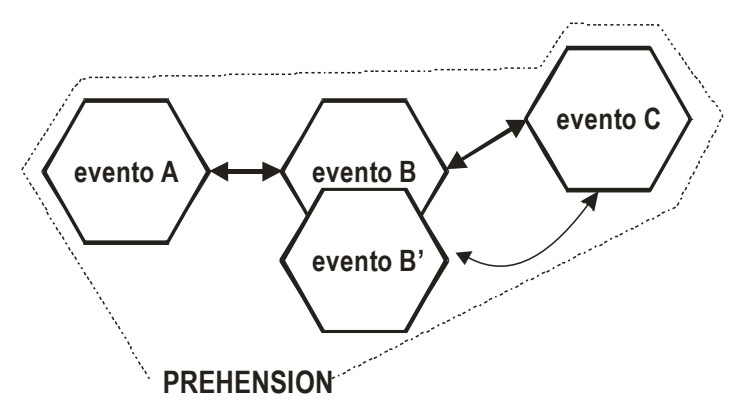

Fonte: Elaborado pelos autores (2020).

Conforme ilustra a Figura 3, para Whitehead (1978), os processos se desenrolam na conexão com outros eventos. Eventos compõem os processos incorporando passado, presente e futuro, formando transições. O futuro é imanente a cada situação presente. A antecipação de proposições diz respeito à constituição e às necessidades da ocasião presente. Essa constituição necessita de um futuro e de um movimento em sua direção. (HERNES, 2008).

Os eventos estão entrelaçados em uma rede dinâmica de interconectividades, ao mesmo tempo em que permanecem abertos a novas conexões e consequentemente a novas formas, mantendo unidas as estruturas e demonstrando vitalidade. Eventos geram mais eventos e também padrões. (COLLINGWOOD, 1945). Entretanto, embora suas conexões sejam dinâmicas, formam a base e criam sentido a partir dos quais os atores agem para organizar em um mundo fluido e complexo. (HERNES, 2008). E qualquer esforço pela busca de ordem e certeza será sempre contraposto pela desordem natural do mundo.

Organizações, sob esse ponto de vista, são sempre tentativas de colocar ordem naquilo que é essencialmente incontrolável. São, portanto, estados provisórios de aparente ordenamento de partes da realidade. Na próxima seção exploramos implicações da noção strong-view de evento para o conceito de organização e para os estudos organizacionais.

\section{POSSIBILIDADES DA ADOÇÃO DA NOÇÃO DE EVENTO DE WHITEHEAD NOS ESTUDOS ORGANIZACIONAIS}

Com base em trabalhos anteriores voltados à compreensão de possibilidades da adoção das ideias de Whitehead para o campo de estudos organizacionais (HUSSENOT; MISSONIER, 2016; HELIN et al. 2014; HERNES, 2008; 2014a; 2014b; COOB JR., 2008), sintetizamos seis princípios, descritos nas subseções a seguir.

\subsection{ORGANIZAÇÃO COMO ESTRUTURA DE EVENTOS}


Hernes $(2008,2014)$ — com base na ontologia de eventos proposta por Whitehead propõe que as organizações sejam vistas como estruturas de eventos ${ }^{10}$. Sua teoria organizacional baseada em eventos (event-based organization theory) fornece as bases para a compreensão das organizações sob o ponto de vista da conexão e constante reconstrução de presente, passado e futuro. Sob esse ponto de vista, a totalidade que compreendemos como organização é resultado de um fluxo de eventos “experienciados" ou vivenciados no momento presente, no qual passado e futuro se encontram e formam a base para o constante emergir da realidade.

De acordo com esse entendimento, toda organização é, ao mesmo tempo, produto de eventos passados e produtora de novidade no evento presente, constituindo um processo de becoming em que os eventos se entrelaçam para se transformarem novamente em algo reconhecido temporariamente como “estável". O termo “estrutura", nesse contexto, é utilizado para demonstrar a força das relações entre eventos interconectados nesse contínuo emergir das organizações, sustentando muitas de suas características e reproduzindo sua totalidade.

Hussenot e Missonier (2016) ilustram a noção de interconexão entre eventos e também a forma como o presente integra passado e futuro: a forma como uma reunião a respeito de um determinado projeto é conduzida está intimamente relacionada aos eventos passados relacionados ao projeto - tais como reuniões anteriores e/ou tarefas antecedentes realizadas pelas pessoas - e aos eventos futuros antecipados - tais como prazos variados e as experiências vividas ou antecipadas que ocorrem no evento atual (actual event). A reunião de fato é definida, portanto, por eventos passados e futuros a respeito do projeto, do mesmo modo que esses eventos passados e futuros podem ser redefinidos durante a ocorrência da reunião. Sucessos do passado podem ser reconsiderados ou ressignificados como fracassos, enquanto prazos futuros e resultados esperados podem ser redefinidos. Para os participantes, o projeto só existe durante essa experiência de encontro entre o presente e os eventos passados e futuros.

Enquanto a continuidade ou repetição de padrões dos inputs gerados pelos eventos passados fornece estabilidade à estrutura organizacional, as descontinuidades permitem o

\footnotetext{
${ }^{10}$ Hernes (2014a; 2014b) é o autor que foi mais longe ao considerar as organizações como estrutura de eventos e construiu fundamentos para uma teoria baseada em eventos. Chia e King (1998) e Chia (1999) já tinham se fundamentado nos estudos de Whitehead para definir organizações como cluster de eventos para demonstrar suas relações, ou considerá-la, conforme sugerido por Nayak e Chia (2011), uma força de desdobramentos imanentes. Da mesma maneira Coob Jr. (2007) sinalizou que o mundo é feito de eventos e que estes não podem ser considerados de maneira isolada, mas sim imbricados em outros eventos.
} 
surgimento do novo. No evento presente, eventos passados e futuros são apreendidos, definidos ou interpretados e redefinidos ou ressignificados. Ao gerar coerência e continuidade, o fenômeno da apreensão (prehension) permite a aplicação da noção de estrutura de eventos às organizações. E, ao gerar descontinuidade, esse mesmo fenômeno permite aplicar as noções de flexibilidade e novidade às estruturas de eventos que formam as organizações.

Segundo Hernes (2008), uma organização deve ser considerada como um emaranhado de processos que se reproduz por meio das ações de diversos atores. Nesse contexto, indivíduo, equipe e organização são níveis indistinguíveis se consideradas as relações imbricadas entre entidades e eventos. Além disso, uma organização não pode ser considerada exclusivamente como social, na medida em que sempre haverá artefatos físicos ou tecnológicos mediadores da interação social. Logo, o mundo físico constrói o mundo social e vice e versa, influenciando-se mutuamente. Não há lados opostos: assim como as pessoas desenvolvem tecnologia, a tecnologia desenvolve as pessoas.

Uma organização não representa uma realidade única, mas um reservatório de possibilidades por meio do qual se pensa e se age, o qual é constituído de pessoas, tecnologias e instituições. Algumas dessas entidades são mais percebidas ou influenciáveis que outras. Os potenciais cursos de ação são tomados na medida em que os diversos atores humanos e não humanos promovem diferentes conexões. Logo, o que uma organização se torna é resultado de como os eventos são conectados ao longo do tempo, ao mesmo tempo em que uma organização se torna o conjunto dos processos que a formam. Entender essa complexidade requer uma jornada incessante de interações entre o acessível e o inacessível. Assim como o uso de metáforas para enfrentar o fenômeno complexo e paradoxal que são as organizações, quando os atores observam uma situação, o que se vê é um emaranhado de conexões. Esse processo não tem forma definitiva, mas oferece várias possíveis interpretações, todas conectadas umas às outras pelo observador até formar uma unidade distinguível.

Em síntese, segundo a Filosofia do Processo de Whitehead, as organizações podem ser consideradas como sociedades/estruturas ou ainda clusters de eventos interconectados que reproduzem sua totalidade mutuamente, por meio da conexão de eventos na atualização momentânea da organização e partir das interpretações de múltiplos atores. (HERNES, 2014b).

\subsection{ONTOLOGIA ORGANIZACIONAL ANCORADA EM SUA TEMPORALIDADE}

Conforme a seção anterior, sob o ponto de vista da Filosofia do Processo as organizações devem ser vistas como processos relacionais estruturados em um emaranhado de eventos em 
permanente construção, os quais são produzidos e reproduzidos ao longo do tempo por meio das ações de diversos atores. Essas ações acessam um reservatório de possibilidades em uma temporalidade ativa que conecta eventos passados e futuros em um presente contínuo.

Ao considerarem o inter-relacionamento ou prehension dos eventos, é possível que atores ajam no presente por meio de um engajamento com os eventos passados e eventos futuros, onde passado e futuro são continuamente definidos e redefinidos em acontecimentos atuais: esse fenômeno se denomina temporalidade. (HUSSENOT; MISSONIER, 2016).

Logo, a apreensão de eventos pelos atores no presente contínuo define os critérios de desempenho organizacional, as características da organização, sua hierarquia e seus objetivos. Tudo o que constitui a organização está em constante definição por meio de uma temporalidade ativa, ou em outras palavras, o tornando-se (becoming) da organização. A temporalidade define a própria ontologia da organização. (HUSSENOT; MISSONIER, 2016; HERNES, 2014a; SCHULTZ; HERNES, 2013). Por exemplo, uma estratégia recebe conteúdos particulares de vários eventos, incluindo bate-papos casuais, apresentações formais, reuniões e sessões de desenvolvimento. Isto mostra que a historicidade de uma estratégia não só define o seu presente, mas também confere potencialidade na forma de seu possível impacto futuro. (HERNES, 2014a).

Uma organização, portanto, deve ser entendida como um presente contínuo formado pela inseparabilidade e dinâmica entre passado, presente e futuro. (HELIN et al., 2014; HERNES, 2020). Eventos passados, presentes e futuros relacionados à organização não estão ontologicamente separados uns dos outros, mas são apreendidos ao mesmo tempo no presente pelos seus atores, os quais os traduzem para sua esfera de operação: “[Eventos] servem ao propósito de prover um senso de onde os atores estão, de onde emergem e para onde estão se direcionando, conforme as articulações [dos eventos] no presente.” (HERNES, 2020, p. 31, grifo no original).

As conexões derivadas das apreensões podem ocorrer de diversas maneiras em um presente contínuo. Enquanto algumas das conexões promovem continuidade e estabilidade da estrutura de eventos, outras promovem novidade e descontinuidade, gerando mudanças.

Uma das principais implicações dessa natureza processual da realidade é a possibilidade de desenvolvimento de uma teoria dinâmica das organizações. Incorporar o tempo como elemento-chave da ontologia organizacional torna possível buscar caminhos para o entendimento das relações entre passado, presente e futuro. Por exemplo, como propõe Hernes (2020), há lacunas em teorias organizacionais a respeito da forma como passado e futuro interagem com o presente. Além disso, o autor distingue os eventos de Whitehead do tempo 
linear e sequencial. Sob o ponto de vista da strong-view de processo, os eventos não se encerram quando acabam. Eventos podem ser ressignificados na medida em que novos eventos surgem.

Essas e outras questões de natureza ontológica evidenciam oportunidades de ampliação do conhecimento a respeito da temporalidade organizacional.

\subsection{EVENTOS COMO UNIDADES DE ANÁLISE ORGANIZACIONAL}

Ainda há um gap na literatura organizacional para tornar explícita a noção de evento como elemento de análise da construção de teoria. Em geral, quando os eventos aparecem, não são sistematicamente considerados como elementos de uma teoria de processo em estudos organizacionais, mas sim como "eventos marcados", com duração sequencial e linear no tempo, ao invés de extensão espaço-temporal. (HERNES, 2014b, p. 265).

Ao considerar o evento como unidade de análise é possível entender a organização como movimento contínuo onde estabilidade e novidade coexistem na mesma realidade, ou seja, considera-se tanto o constante emergir das organizações quanto a sustentação de suas características, onde os atores continuamente redefinem e reproduzem uma estrutura. Essa dinâmica é expressa no evento atual (actual event) por meio da apreensão dos atores. Em outras palavras, a organização só existe no presente, ou seja, na estrutura de eventos experienciada na realidade. (HUSSENOT; MISSONIER, 2016).

Hernes (2020) menciona, por exemplo, a noção de agência do presente para explicar a forma como os eventos do passado e do futuro são selecionados e organizados pelos atores organizacionais como forma de construir os eventos do presente. Os eventos, portanto, assumem uma centralidade na teorização a respeito da natureza organizacional ao se tornarem explicativos da dinâmica temporal que confere direcionalidade aos atores. Ou seja, os eventos criam um senso de continuidade e descontinuidade que revela o "tornando-se" (becoming) organizacional. Permitem, portanto, avançar em direção a teorias organizacionais mais complexas e alinhadas com uma ontologia processual.

\subsection{ORGANIZAÇÃO COMO PROCESSO CONTÍNUO}

Sob a perspectiva de processo, quando as organizações são vistas como eventos não podem ser reificadas conforme propõe a visão funcionalista e substantiva do que se entende por “organização”. Organizações como eventos são emaranhados de relações com plasticidade dinâmica. Segundo Hernes (2008), em lugar de avaliar uma mudança organizacional, é mais 
viável entender a complexidade do processo em torno da mudança, pois o que é já não é mais, mas sim uma formação constante de becoming. Por exemplo, quando se percebe uma organização como se estivesse "lá" em termos espaciais e temporais, perde-se de vista sua natureza de formação contínua. E se está em constante emergência, a rigor uma organização não pode mudar porque mudança significa tornar algo que "era" em algo que "é". Logo, em uma visão strong-view de processo, a percepção de transformação ou mudança de uma organização deve ser vista como um evento dentre outros eventos, sem que seja possível atribuir causalidade a um único evento ou substancialidade à mudança. (HERNES, 2008).

De acordo com essa visão atomística, tudo é possível nesse processo contínuo de emergência da realidade organizacional, pois há uma infinidade de combinações possíveis. Mas as combinações que se tornam reais dependem da habilidade dos atores criarem essas conexões. Por exemplo, gerentes não podem fazer qualquer combinação de fatores quando estão reorganizando um departamento. É preciso verificar os recursos disponíveis, como estão sendo alocados, quais os objetivos da alta administração, dentre outros elementos. Porém, Whitehead (1993) enfatiza que há mais liberdade de escolha para se conectar a outras possibilidades do que se imagina e do que se deseja conceder. Entretanto, uma vez que a escolha é feita, influenciará o que acontecerá mais tarde. A visão atomística do mundo, portanto, inspira o entendimento de como algumas coisas emergem e outras não. O mundo parece solto, mas escolhas conduzem às conexões mais rápidas e mais prováveis entre os eventos.

Pode-se considerar, portanto, que as organizações consistem em uma combinação criativa de fatores, incluindo os atores humanos. (HERNES, 2008). Por exemplo, uma equipe de trabalho pode ser percebida exclusivamente como uma parte da "engrenagem organizacional' '. Porém, esta mesma equipe pode desenvolver uma inovação para alavancar os negócios e melhorar a imagem da organização. Passará, portanto, a ser percebida ou interpretada como um novo tipo de entidade. Este exemplo demonstra como entidades podem emergir de novas combinações e gerar novas relações entre os aspectos organizacionais. Logo, os atores organizacionais estão sempre em um estado de becoming ou de se tornarem algo "a mais"' conforme as relações com outros atores.

A natureza processual contínua da organização também se revela na constituição mútua de seus elementos. Por exemplo, um membro de uma equipe ocupa um papel gerencial enquanto comanda aquela equipe em particular e durante aquele tempo. O gerente "constrói”, a equipe, assim como a equipe "constrói”’ o gerente. De forma semelhante, se uma equipe está envolvida na busca do desenvolvimento de uma nova tecnologia, a equipe e a tecnologia se desenvolvem mutuamente. (HERNES, 2008). 
As organizações, portanto, devem ser vistas como processo contínuo formado por múltiplos movimentos fluidos e entrelaçados entre experiência concreta e abstração. Sob esse ponto de vista, Whitehead é central para o entendimento da organização como processo na medida em que a visão relacional é capaz de explicar como as coisas se combinam no processo de becoming, enquanto rejeita substâncias absolutas e, por conseguinte, categorizações. Sob essa perspectiva de processo, as organizações são sempre fenômenos que emergem por meio de conexões contínuas. (HERNES, 2008).

\subsection{ORGANIZAÇÃO COMO RESULTADO DE MECANISMOS DE ESTABILIZAÇÃO DINÂMICA}

No campo da teoria organizacional, as organizações têm sido vistas como entidades ou substâncias que se adaptam ao ambiente. Consequentemente, são interpretadas como entidades estáveis que mudam ao se adaptarem gradualmente às mudanças do ambiente externo. Sob a perspectiva strong-view de processo, o foco é o inverso: a estabilidade, não a mudança, é o elemento a ser explicado em mundo que está em constante mudança. A organização, nesse contexto, é uma tentativa de estabilização em um mundo dinâmico caracterizado pela constante emergência da realidade. (HERNES, 2008).

Ao criarem uma organização baseada em certos modelos e caracterizada por relativa estabilidade, os atores buscam estabilizar uma imagem de um estado desejado ou um conjunto de ideias e princípios. Entretanto, segundo Hernes (2008) a metafísica de qualquer organização é sempre um estado de becoming. Portanto, a ação no mundo só pode atender ao que se tem em foco, cuja seleção subjetiva é limitada se comparada ao todo dos acontecimentos. Isso significa que não há organização sem intenção, mesmo que as coisas não aconteçam conforme o planejado. As coisas também surgem quando não há uma intenção relacionada, ou seja, também acontecem quando as pessoas continuam a fazer seu trabalho rotineiro.

Neste contexto, se faz necessária alguma base para convergência dos processos e em direção a algo "a mais". A rotinização de atividades forma essa base para a criação do novo, ao mesmo tempo em que fornece uma sensação de estabilidade ao processo ao unir eventos em padrões que possibilitam o "tornar a fazer".

Outro mecanismo que confere ao mesmo tempo estabilidade e flexibilidade aos processos são os significados que conectam os eventos espaço-temporalmente. Por exemplo, conforme afirmam Rantakari e Vaara (2017), enquanto algumas perspectivas usam a narrativa como forma de representação, outras consideram a narrativa como construção de significados. 
No início de uma vida organizacional, por exemplo, quando há baixo nível de compartilhamento e imbricamento, os eventos têm significado intrínseco. Entretanto, no processo de construção da identidade organizacional, os eventos vão fazendo sentido por meio de metáforas usadas nas narrativas. E conforme a organização vai expandindo e se tornando mais complexa, aumenta a importância da legitimidade. É a partir deste momento que metáforas de modelos organizacionais são adotadas em maior medida a partir daquilo que foi socialmente construído e aceito. (HERNES, 2008).

Alguns trabalhos empíricos têm buscado entender os mecanismos de estabilização dinâmica e a relação entre estabilidade e novidade no contexto organizacional. (WEICK, 1995; CHIA, 1998; CARTER, 2012; HERNES, 2014a; HUSSENOT; MISSONIER, 2016). Hussenot e Missonier (2016), por exemplo, perceberam esse gap e desenvolveram uma abordagem baseada em eventos, a qual considera ao mesmo tempo estabilidade e novidade como elementos coexistentes do processo de emergência organizacional. Segundo os autores, abordagens anteriores em teoria organizacional consideravam estabilidade e mudança como estados distintos. Entretanto, a partir de observação empírica, verificaram o entrelaçamento entre estabilidade e novidade sob a lente dos eventos conforme a ontologia processual de Whitehead. Com base em um estudo de caso do desenvolvimento de uma ferramenta de gestão de competências no setor bancário, demonstrou-se a forma como os eventos se constituem ao mesmo tempo em atos de estabilidade e de mudança.

\subsection{ORGANIZAÇÃO COMO REITERAÇÃO DE PADRÕES}

Em lugar de pensar que as coisas persistem, Whitehead (1978) sugere o termo reiteração, o qual significa re-manifestação ou reaparecimento. Dessa forma, busca evitar a impressão de que a semelhança significa estabilidade. Ao contrário, reiteração é uma sucessão de contrastes de padrões. Estes padrões se manifestam subjetivamente, o que implica dizer que a emergência e o desenvolvimento de uma organização envolvem reiterações de padrões. (HERNES, 2008). Cooper (2005) enfatiza que continuar agindo, ou reiterando, cria oportunidades para conexões que geram a percepção de instabilidade, mas também para conexões que geram novidade. Consequentemente, o intencional pode não acontecer e o não intencional pode conduzir a algo novo.

Empiricamente, observa-se como esse fenômeno de reiteração ocorre nas organizações por meio da emergência de abstrações como papéis, funções e planos. Quando combinados, esses elementos podem dar origem a modelos organizacionais, tais como as formas burocráticas 
de controle. A frequência das abstrações reiteradas cria a ilusão de estabilidade como sinônimo de real. Ao serem dados como certos (taken for granted), esses modelos organizacionais passam a ser vistos quase como um fenômeno natural que transcende ou restringe a experiência concreta. (HERNES, 2008).

\section{CONSIDERAÇÕES FINAIS}

O desenvolvimento científico dos campos de estudos de administração e de organizações passa necessariamente pelo aprofundamento de questões ontológicas, epistemológicas, teóricas e metodológicas. Neste trabalho, adotamos uma abordagem introdutória à questão do uso do conceito de evento, com ênfase nas possibilidades apresentadas pela Filosofia do Processo de Whitehead e pelo recente interesse de estudiosos de organizações na visão strong-view de processo aplicada à pesquisa.

Inicialmente, apontamos para a necessidade de superação da visão de realidade como conjunto de substâncias estáveis. Ao contrário, uma strong-view de processo implica em uma ontologia de movimento e de dinâmica. O “ser" é substituído pelo “tornando-se”. Logo, organizações não são entidades estáveis sujeitas à transformação a partir de um ambiente externo. Organizações são processos de becoming cuja estabilização é perceptual e sempre provisória.

Epistemologicamente, apontamos para a necessidade de superar a possibilidade de conhecimento pela via representacional. Uma visão processual da organização, tal como a proposta aqui, demanda que a busca pelo conhecimento passe pela performatividade, pela experiência, pelo sensível e pelo simbólico. O real, sob esse ponto de vista, é sempre um acordo entre a experiência coletiva e individual dos atores humanos em interação com o objetivo e o subjetivo.

Sob o ponto de vista teórico, ao contrário da ideia de teoria como simplificação, proposta pela ciência normal, as teorias derivadas da Filosofia do Processo seguem na direção da complexidade teórica. Conforme propõe Tsoukas (2016), a complexidade organizacional demanda o desenvolvimento de teorias conjuntivas, capazes de explicar mecanismos de natureza processual, temporal, relacional e interpretativos. Trata-se, portanto, de evitar as explicações disjuntivas voltadas à separação e à simplificação da compreensão dos elementos organizacionais: "Nós valorizamos o tempo, entretanto o excluímos! Reconhecemos a complexidade do mundo, entretanto negamos essa complexidade em nossas teorias." (TSOUKAS, 2016, p. 137, tradução nossa). Trata, ainda, do entendimento dos comportamentos 
interrelacionados que emergem a partir do organizing e dão origem à percepção de estabilidade organizacional. Trata-se, também, da capacidade de explicar a natureza imbricada dos eventos que dão origem e conferem trajetória aos processos.

Quanto às teorias criticadas por serem estáticas ou por enfatizarem estabilidade ao invés de mudança, não se trata de abandonar noções de estabilidade e substituí-las por movimento (MORGESON et al., 2015). É necessário considerar novidade e estabilidade como partes de uma mesma ação (HUSSENOT; MISSONIER, 2016). Quando os eventos são evidenciados, de acordo com o significado proposto por Whitehead (1929, 1978, 1993), as combinações potenciais de variáveis são numerosas, pois os eventos "perturbam" as condições estáveis das coisas: "Mesmo que alguns eventos só ocorram por um breve momento, podem alterar permanentemente as características ou recursos existentes do ambiente de trabalho ou podem gerar novos. [...] além de poder causar eventos subsequentes ao longo do tempo" (MORGESON et al., 2015, p. 531, grifo nosso).

Os eventos também mantêm a fluidez necessária para o processo de teorização na medida em que servem de base para separar as abstrações teóricas sobre os sujeitos, os objetos, as normas, os procedimentos, os julgamentos e suas relações e representações, das ações com seus objetivos e seus movimentos regimentados. Entretanto, os eventos ainda são pouco considerados como unidades de análise por serem difíceis de serem “capturados" na medida em que é preciso resistir em mostrar uma única maneira de se fazer as coisas e sim, de maneira performativa, seguir o fluxo do processo em um contínuo becoming do mundo, considerando sua multiplicidade e não garantindo a repetição consistente, mas por meio da imitação encontrar a diferença, criando por meio desta diferenciação a qualidade do novo (HELIN et al., 2014).

Sob o ponto de vista metodológico, técnicas de pesquisa orientadas à noção strong-view de evento precisam ser desenvolvidas, pois os métodos atuais parecem inadequados para se fazer investigação sob essa perspectiva ontológica. Métodos antigos e recentes precisam ser desenvolvidos, adaptados ou modificados. O principal desafio recai em “o que" medir e como medir. Quais são os indícios relevantes de eventos? Como captar eventos enquanto estão ocorrendo? Como identificar seus desdobramentos e conexões? Quais as implicações da emergência e reprodução de eventos? Embora sejam muitos os questionamentos e desafios, aplicar o pensamento processual nos estudos de administração e de organizações pode inspirar novas ideias sobre como as coisas são e como se tornam (become).

Esses e outros aspectos apontados nesse trabalho são em si mesmos eventos com múltiplas possibilidades de conexão. Assumir um posicionamento processual na pesquisa e teorização organizacional pode nos conduzir, portanto, a diversos caminhos e resultados. 
Primariamente, consideramos essencial uma etapa de sensibilização junto aos acadêmicos do campo, de forma a impregnar nossas investigações de uma visão mais complexa e processual da realidade. Em um segundo momento, esperamos que as pesquisas contaminem positivamente a visão de mundo dos responsáveis diretos pela administração de organizações e instituições. Acreditamos que uma visão processual de natureza strong-view contribuirá significativamente para a superação de explicações simplificadoras da realidade. Favorecendo, portanto, a construção de soluções complexas para problemas igualmente complexos.

Finalmente, esperamos ter criado condições para despertar maior interesse a respeito do papel que os eventos - aqui entendidos sob o ponto de vista da Filosofia do Processo de Whitehead - exercem nas organizações e na prática da administração.

\section{REFERÊNCIAS}

CARTER, H. Process philosophy in five easy pieces. Amazon Digital Services, Inc., 2012.

CHIA, R.; KING, W. I. The organizational structuring of novelty. Organization, v. 5, p. 461478, 1998.

COOB JR., J. B. A glossary with alphabetical index to technical terms in process and reality: Whitehead word book. Claremont, CA, P\&F Press, 2008.

COOLINGWOOD, R. G. The idea of nature. Oxford: The Clarendon Press, 1945.

COOPER, R. Relationality. Organization Studies, v. 26, n. 11, p. 1689-1710, 2005.

DURANT, R.; VAARA, E. Causation, counterfactuals and competitive advantage. Strategic Management Journal, v. 30, n. 12, p. 1245-1264, 2009. Disponível em:

<https://www.researchgate.net/publication/50231164_Causation_counterfactuals_and_compet itive advantage>. Acesso em: 12 fev. 2020.

FOUCAULT, M. As palavras e as coisas. São Paulo: Martins Fontes, 1999.

GOODE, W.J.; HATT, P.K. Métodos em pesquisa social. 7. ed. São Paulo: Nacional, 1979.

HARDY, C.; THOMAS, R. Power and process: the production of 'knowing' subjects and 'know' objects. In: LANGLEY, A.; TSOUKAS, H. (Ed.). The SAGE handbook of process organization studies. London: SAGE Publications Ltd, 2017, p. 465-480.

HELIN, J.; HERNES, T.; HJORTH, D.; HOLT, R. The Oxford handbook of process philosophy \& organization studies. United Kingdom: Oxford University Press, 2014.

HERNES, T. Understanding organization as process: theory for a tangled world. London: Routledge, 2008. 
HERNES, T. A process theory of organization. United Kingdom: Oxford University Press, 2014a.

HERNES, T. Alfred North Whitehead (1861-1947). In: HELIN, J.; HERNES, T.; HJORTH, D.; HOLT, R. (Ed.). The Oxford handbook of process philosophy \& organization studies. United Kingdom: Oxford University Press, 2014b, p. 255-271.

HERNES, T. Process as the becoming of temporal trajectory. In: LANGLEY, A.; TSOUKAS, H. (Ed.). The SAGE handbook of process organization studies. London: SAGE Publications Ltd, 2017, p. 601-606.

HERNES, T. Events and the becoming of organizational temporality. In: REINECKE, J.; SUDDABY, R.; LANGLEY, A.; TSOUKAS, H. (Ed.). Time, Temporality, and History in Process Organization Studies. Oxford University Press, 2020, p. 29-43.

HOLT, R.; MUELLER, F. Wittgenstein, Heidegger and drawing lines in organization studies.Organization Studies, v. 32, p. 67-84, 2011.

HUSSENOT, A.; MISSONIER, S. Encompassing stability and novelty in organization studies: an events-based approach. Organization Studies, v. 37, n. 4, p. 523-546, 2016.

KOSELLECK, R. Uma história dos conceitos: problemas teóricos e práticos. Estudos Históricos, Rio de Janeiro, v. 10, p. 134-146, 1992.

LANGLEY, A.; TSOUKAS, H. Introduction: process thinking, process theorizing and process researching. In: LANGLEY, A.; TSOUKAS, H. (Ed.). The SAGE handbook of process organization studies. London: SAGE Publications Ltd, 2017, p. 1-25.

MAYS, N.; ROBERTS, E.; POPAY, J. Synthesising research evidence. In: FULOP, N.; ALLEN, P.; CLARKE, A.; BLACK, N. (Ed.). Studying the organisation and delivery of health Services: research methods. London: Routledge, 2001, p. 188-220.

MATITZ, Q. R. S.; VIZEU, F. Construção e uso de conceitos em estudos organizacionais: por uma perspectiva social e histórica. RAP, v. 46, n. 2, p. 577-598, 2012. Disponível em: <http://bibliotecadigital.fgv.br/ojs/index.php/rap/article/view/7099/5653 >. Acesso em: 20 mar. 2020.

MORGESON, F. P; MITCHELL, T. R.; LIU, D. Event system theory: an event-oriented approach to the organizational sciences. Academy of Management Review, v. 40, n. 4, p. 515-537, 2015.

PARÉ, G.; TRUDEL, M. C.; JAANA, M.; KITSIOU, S. Synthesizing information systems knowledge: a typology of literature reviews. Information \& Management, v. 52, p. 183-199, 2015. Disponível em:

$<$ https://edisciplinas.usp.br/pluginfile.php/4150288/mod_resource/content/1/2.4.Pare\%20et\% 20al.\%202015\%20-\%20literature\%20review.pdf>. Acesso em: 02 set. 2019.

RANTAKARI, A. VAARA, E. Narratives and processuality. In: LANGLEY, A.; TSOUKAS, H. (Ed.). The SAGE handbook of process organization studies. London: SAGE Publications Ltd, 2017, p. 271-285. 
SELTTIZ, C.; JOHODA, M.; DEUTSEH, M.; COOK, S. W. Métodos de pesquisa nas relações sociais. São Paulo: EPU, 1974.

SCHULTZ, M.; HERNES, T. A temporal perspective on organizational identity.

Organization Science, v. 24, n. 1, p. 1-21, 2013. Disponível em:

$<$ https://www.researchgate.net/publication/260140232_A_Temporal_Perspective_on_Organiz ational Identity>. Acesso em: 19 dez. 2018.

TSOUKAS, H. Don't Simplify, complexify: from disjunctive to conjunctive theorizing in organization and management studies. Journal of Management Studies, v. 54, p. 132-153, 2016. DOI. 10.1111/joms.12219. Disponível em:

<https://onlinelibrary.wiley.com/doi/epdf/10.1111/joms.12219>. Acesso em: 27 fev. 2021.

WEICK, K. E. Sensemaking in organizations. Sage Publications: London, 1995.

WHITEHEAD, A. N. The aims of education and other essays. Macmillan: New York, 1929.

WHITEHEAD, A. N. Process and reality. New York: The Free Press, 1978.

WHITEHEAD, A. N. O conceito de natureza. São Paulo: Martins Fontes, 1993. 